functional class I, II or III. An open-label prospective trial of 138 adults patients (120 female and 18 male) with OA was conducted. Patients with OA in whom the knee or hip was the primary source of pain were included. Patients received either 12.5 $\mathrm{mg}$ or $25 \mathrm{mg}$ rofecoxib once daily. Patients whom did not benefit from $12.5 \mathrm{mg}$ were allowed to receive $25 \mathrm{mg}$. Clinical efficacy and safety were monitored during a 6 week of therapy. Clinical efficacy were evaluated by comparing pretreatment and treatment values of the WOMAC (Western Ontario and McMaster Universities Osteoarthritis Index), investigator global assesment of disease status and Hip or Knee osteoarthritis and Lequesne-Algofunction Index. Pysical examination, vital signs, body weight, laboratory examinations and adverse event reporting were monitored for safety purposes.

Results The Lequesne-Algofunction Index and WOMAC demonstrated that patients with knee osteoarthritis were significantly better starting from the 3 rd visit $(p<0.001)$. The number of patients with hip osteoarthritis $(n=9)$ were very low. Thus the evaluations of hip efficacy did not reach to statistical significance eventhough the indexes were showing a numerical improvements in hip osteoarthritis patients. The investigator global assessment of disease status were significantly better in 4th and 5th visits comparing to $3 \mathrm{rd}$ visit. The efficacy data shows that, rofecoxib $12.5 \mathrm{mg}$ once daily or $25 \mathrm{mg}$ once daily provides efficacy clinically comparable with the pretreatment period on all primary end points. Treatment with rofecoxib was generally well tolerated. There were no serious adverse event during the entire period.

Conclusion The Lequesne-Algofunction Index and WOMAC demonstrated that patients with knee osteoarthritis were significantly better starting from the 3rd visit $(\mathrm{p}<0.001)$. The number of patients with hip osteoarthritis $(n=9)$ were very low. Thus the evaluations of hip efficacy did not reach to statistical significance even though the indexes were showing a numerical improvements in hip osteoarthritis patients. The investigator global assessment of disease status were significantly better in 4 th and 5th visits comparing to 3 rd visit. The efficacy data shows that, rofecoxib $12.5 \mathrm{mg}$ once daily or $25 \mathrm{mg}$ once daily provides efficacy clinically comparable with the pretreatment period on all primary end points. Treatment with rofecoxib was generally well tolerated. There were no serious adverse event during the entire period.

Co-authors are: Members of the Rofecoxib Osteoartrhitis Group* as follows: Afsar Levent MD, Akarirmak Ulku MD, Akinci Ayse MD, Akkoc Nurullah MD, Aktuglu Kemal MD, Akyuz Gulseren MD, Alper Serap MD, Altinmakas Mehmet MD, Arasil Tansu MD, Asik Mehmet MD, Atalay Fatma MD, Atik Sahap MD, Berk Haluk MD, Direskenli Haner MD, Erdogan Fahri MD, Ertenli Ihsan MD, Eskiyurt Nurten** MD, Gedikoglu Oner MD, Goncu Kamil MD, Guzel Rengin MD, Hepguler Simin MD, Kabasakal Yasemin MD, Kuru Omer MD, Kucukoglu Selcuk MD, Oncel Sema MD, Onen Fatos MD, Suleyman Ozbek MD, Ahmet Ozgul MD, Sepici Vesile MD, Sindel Dilsad MD, Togrul Emre MD, Yurtkuran Merih MD.

"In alphabetical order.

**Clinical study co-ordinator.
AB0142 A CASE OF DIFFUSE IDIOPATHIC SKELETAL HYPEROSTOSIS (DISH) WITH AN EXTREMELY RARE COMPLICATION

${ }^{1} \mathrm{H}$ Kocyigit, ${ }^{2} \mathrm{~N}$ Erdogan, ${ }^{2} \mathrm{E}$ Uluc, ${ }^{3} \mathrm{~N}$ Hizli, ${ }^{4} \mathrm{O}$ Ozdemir, ${ }^{2} \mathrm{O}$ Polat. ${ }^{1}$ Physical Medicine and Rehabilitation; ${ }^{2}$ Radiology; ${ }^{3}$ Rheumatology; ${ }^{4}$ Otorhinolaryngology, Izmir Ataturk Training Hospital, Izmir, Turkey

\subsection{6/annrheumdis-2001.404}

Background Diffuse idiopathic skeletal hyperostosis (DISH) is a disorder characterised by new bone growth at entheses. In the literature, it has been reported that the anterior bony excrescences in the cervical region due to thickening and ossification of the anterior longitudinal ligament may be up to maximum 12 $\mathrm{mm}$ thick. Advanced forms of cervical DISH may give rise to dysphagia, cervical myelopathy, and very rarely dyspnea. We present a 70-year-old man with advanced DISH whose only complaint was severe dyspnea. Cervical computed tomography revealed the large excrescences reaching to $15 \mathrm{~mm}$ in thickness. Surgical excision of his anterior cervical osteophytes resulted in relief of his symptoms.

Objectives

Methods

Results

Conclusion

\section{AB0143 GASTROPROTECTIVE EFFECT OF LANSOPRAZOLE IN OSTEOARTHRITIS PA-TIENTS LONG-TIME RECEIVING DICLOPHENAC}

SA Alexeenko, EL Nikonov, AG Amathnyak. Internal Medicine, Far Eastern State Medical University, Khabarovsk, Russia

\subsection{6/annrheumdis-2001.405}

\section{Background}

Objectives To compare efficiency and safety of 4-week treatment by nimesulid, diclophenac and diclophenac in a combination with lansoprazole in osteoarthritis patients.

Methods We observed 167 patients (130 women and 37 men, mean age 54 years). During 4 weeks in the first group 74 patients received diclophenac $100 \mathrm{mg}$ per day, in the second group 31 patients - diclophenac in a combination with lansoprazole $30 \mathrm{mg}$ per day and in the third group 62 patients received nimesulid $200 \mathrm{mg}$ per day. Before and after 4 -weeks treatment were estimated of a clinical symptomatology, upper GI endoscopy, 24 h Ò̂-metry (Digitrapper MkIII, Synectics, Sweden), histological research of biopsy of a mucosa from antral part of a stomach. For a estimate of clinical effi-ciency was used a questionnaire of a quality of life SF-36.

Results The clinical efficiency of therapy by diclophenac or nimesulid in osteoarthritis patients was comparable. The frequency of development of erosions and ulcers of a stomach was higher at diclophenac group (41\%), than at nimesulid group (24\%). The combination of diclophenac and lansoprazole has allowed to lower frequency of development of erosions and ulcers of a stomach mucosa to $16 \%$. Positive dynamics of morpho-functional of parameters of a stomach mucosa in lansoprazole group was found.

Conclusion Our results prove gastroprotective effect of lansoprazole. The application lansoprazole for osteoarthritis patients long-time receiving diclophenac is accompanied by positive dynamics morphofunctional parameters of a mucosa of a 